\title{
Linear Stapling Device with Pre-attached Bioabsorbable Polyglycolic Acid Felt Reduces Postoperative Pancreatic Fistula After Distal Pancreatectomy
}

\author{
YO-ICHI YAMASHITA ${ }^{1}$, EIJI TSUJITA ${ }^{2}$, AKIRA CHIKAMOTO ${ }^{1}$, KATSUNORI IMAI $^{1}$, \\ TAKAYOSHI KAIDA ${ }^{1}$, TAKANOBU YAMAO $^{1}$, NAOKI UMEZAKI ${ }^{1}$, \\ SHIGEKI NAKAGAWA ${ }^{1}$, DAISUKE HASHIMOTO ${ }^{1}$ and HIDEO BABA ${ }^{1}$ \\ ${ }^{1}$ Department of Gastroenterological Surgery, Graduate School of Life Sciences, \\ Kumamoto University, Kumamoto, Japan; \\ ${ }^{2}$ Department of Hepato-Biliary-Pancreatic Surgery, National Kyushu Cancer Center, Fukuoka, Japan
}

\begin{abstract}
The incidence of postoperative pancreatic fistula (POPF) remains high at approximately $30 \%$ of cases with distal pancreatectomy (DP) and is associated with higher incidence of life-threatening complications. However, the most appropriate closure technique for the pancreatic stump during DP remains controversial. We, herein, present details of the use of a linear stapling device with pre-attached bioabsorbable polyglycolic acid (PGA) felt for pancreatic stump closure during DP. Grade B or C POPF occurred in only one case (5\%) among 22 consecutive patients.
\end{abstract}

Distal pancreatectomy (DP) is standard procedure for tumors of the pancreas located to the left of the portal/superior mesenteric vein. The incidence of postoperative pancreatic fistula (POPF) remains high at approximately $30 \%$ of cases and is associated with higher incidence of life-threatening complications (1). Various techniques have been applied for pancreatic stump closure, such as stapling (1), teres ligament patching (2), fibrin sealing (3), TachoSil ${ }^{\circledR}$ (4) patching and panreaticojejunostomy (5); however, the most appropriate closure technique for the pancreatic stump during DP remains controversial. Due to the increase of the laparoscopic approach

All Authors' authorships for this work were confirmed by the guideline of ICMJE.

Correspondence to: Yo-ichi Yamashita, MD, PhD, FACS, Department of Gastroenterological Surgery, Graduate School of Life Sciences, Kumamoto University, 1-1-1 Honjyo, Chuo-ku, Kumamoto 860-8556, Japan. Tel: +81 963735211, Fax: +81 963714378, e-mail: y-yama@kumamoto-u.ac.jp

Key Words: Polyglycolic acid (PGA) felt, distal pancreatectomy (DP), postoperative pancreatic fistula (POPF). to DP, staple closures have recently become more common for pancreatic stump closure. Herein, we present the details of the use of a linear stapling device with pre-attached bioabsorbable polyglycolic acid (PGA) felt for pancreatic stump closure during DP.

\section{Patients and Methods}

From 2013 to 2014, staplers without PGA felt (Endo GIA ${ }^{\mathrm{TM}}$ with Tri-Staple $^{\mathrm{TM}}$ technology; black or purple reload; $60-\mathrm{mm}$ long; Covidien Japan Inc., Tokyo, Japan) were applied to 20 consecutive patients with pancreatic tumors for the pancreatic stump closure during DP. Beginning in 2015 and extending to March 2016, a linear stapling device with pre-attached PGA felt (Endo GIA ${ }^{\text {тм }}$ Reinforced Reload with Tri-Staple ${ }^{\mathrm{TM}}$; black reload; 60-mm long; Covidien Japan Inc.) was applied to 22 consecutive patients. The PGA felt $(+)$ group included 8 patients $(40 \%)$ with laparoscopic DP and the PGA (-) group included 7 patients $(32 \%)$ with laparoscopic DP.

Details of the liner stapling device with PGA felt pre-attached (Endo GIA $^{\mathrm{TM}}$ Tri-Staple $^{\mathrm{TM}}$ Technology) are shown in Figure 1. We used the $60-\mathrm{mm}$ black cartridge with pre-attached PGA felt bilaterally (NEOVEIL ${ }^{\circledR} 0.15 \mathrm{~mm}$ in thickness) (Figure 1A). When the reload was closed and fired, the incorporated staples were Bformed with closed heights of 1.75-2.0-2.25 mm. NEOVEIL ${ }^{\circledR}$ is a bioabsorbable (within 15 weeks) reinforcement material made from PGA (Figure 1B). It is also porous, making tissue ingrowth possible (Figure 1C).

The operative schemas of the case with laparoscopic DP are shown in Figure 2. The parenchyma of the pancreas just above the portal/superior mesenteric vein was isolated and controlled with tape (Figure 2A). The pancreas was closed using staplers with PGA felt (Figure 2B). To avoid multiple applications of the stapler, we routinely use a cartridge that is $60 \mathrm{~mm}$ in length. When the stapler with PGA felt is taken off, the tip of PGA felt is not divided (Figure 2C). Gentle handling of the stapler is especially needed during removal of the stapler from the pancreas.

The rate of POPF was compared between the two groups, with and without PGA felt, using the $\chi^{2}$ test. POPF was evaluated using 


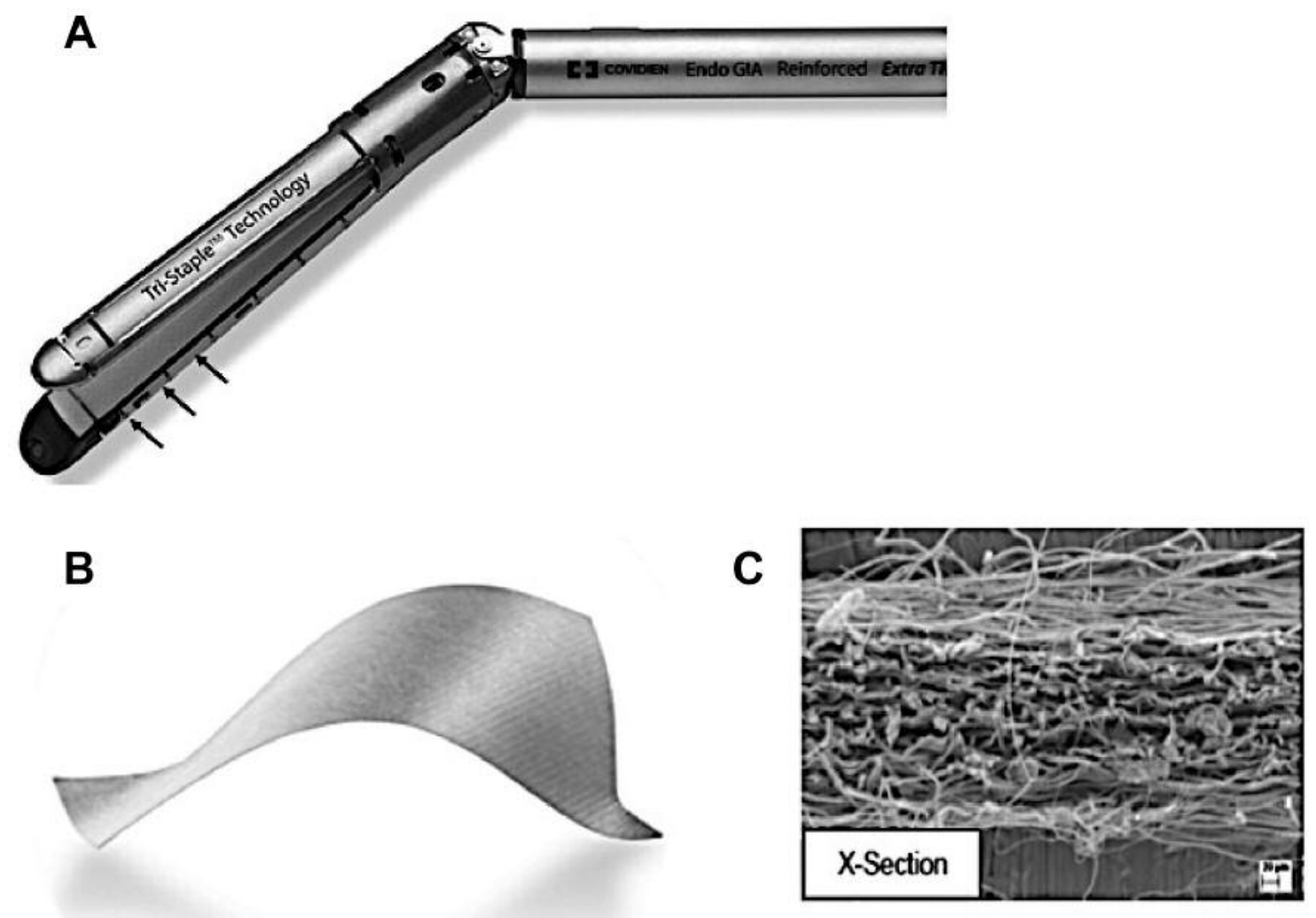

Figure 1. (A) The stapler with polyglycolic acid (PGA) felt (Endo GIA TM Tri-Staple ${ }^{T M}$ Technology) is shown. The arrow indicates PGA felt preattached to the surfaces of the black cartridge bilaterally (NEOVEIL ${ }^{\circledR} 0.15 \mathrm{~mm}$ in thickness). $(B)$. NEOVEIL ${ }^{\circledR}$ is an absorbable reinforcement material made from PGA. (C) Photo of NEOVEL ${ }^{\circledR}$ in a scanning electron microscope $(\times 100)$. NEOVEL ${ }^{\circledR}$ is a porous material, such that tissue ingrowth is possible.

the International Study Group on Pancreatic Fistula (ISGPF) guidelines (6). All analyses were performed with $\mathrm{JMP}^{\circledR}$ Pro 12 (SAS Institute Inc., Cary, NC, USA). All $p$-values less than 0.05 were considered to indicate statistical significance.

\section{Results}

In all 22 patients to whom staples with PGA felt were applied, no accident, such as bleeding, failure of stapling or pleural applications of staplers, occurred. A comparison of the rates of POPF between the two groups is summarized in Table I. The POPF rate in the PGA felt (+) group was decreased to $18 \%$ (4/22 cases) compared to $45 \%$ (9/20 cases) in the PGA felt (-) group; however, the difference was not statistically significant $(p=0.0583)$. The rate of Grade B or C POPF was significantly decreased in the PGA felt (+) group (5\% vs. 30\%, $p=0.0216)$. There was no hospital death in either group; however, there was one Grade C POPF case that required angiography to control the hemorrhaging due to a pseudoaneurysm at the splenic artery in the PGA felt (-) group.

\section{Discussion}

There are two possible reasons for POPF in DP after division of the pancreas using staples; one is the stapling error of the main pancreatic duct at the pancreatic stump and the other is the tearing of the pancreatic parenchyma at the pancreatic stump. From the experiences of pressure tolerance studies using porcine or bovine pancreases, the major cause of POPF after staple applications is the tearing of the pancreatic parenchyma at the pancreatic stump (7). To avoid tearing the pancreatic parenchyma using a stapler with PGA felt, gentle compression of the parenchyma to 1.75-2.0-2.25 mm thickness would be the first priority. According to the instruction manual, the applicable thickness of the tissue should be 1.95 to $2.7 \mathrm{~mm}$. The thickness of the adult human pancreatic body typically exceeds $3.0 \mathrm{~mm}$. We went ahead and applied this stapler to the division of the pancreas because the pancreatic parenchyma is relatively soft. To the best of our knowledge, no technical difficulties during use of the stapler with PGA felt have been reported. 

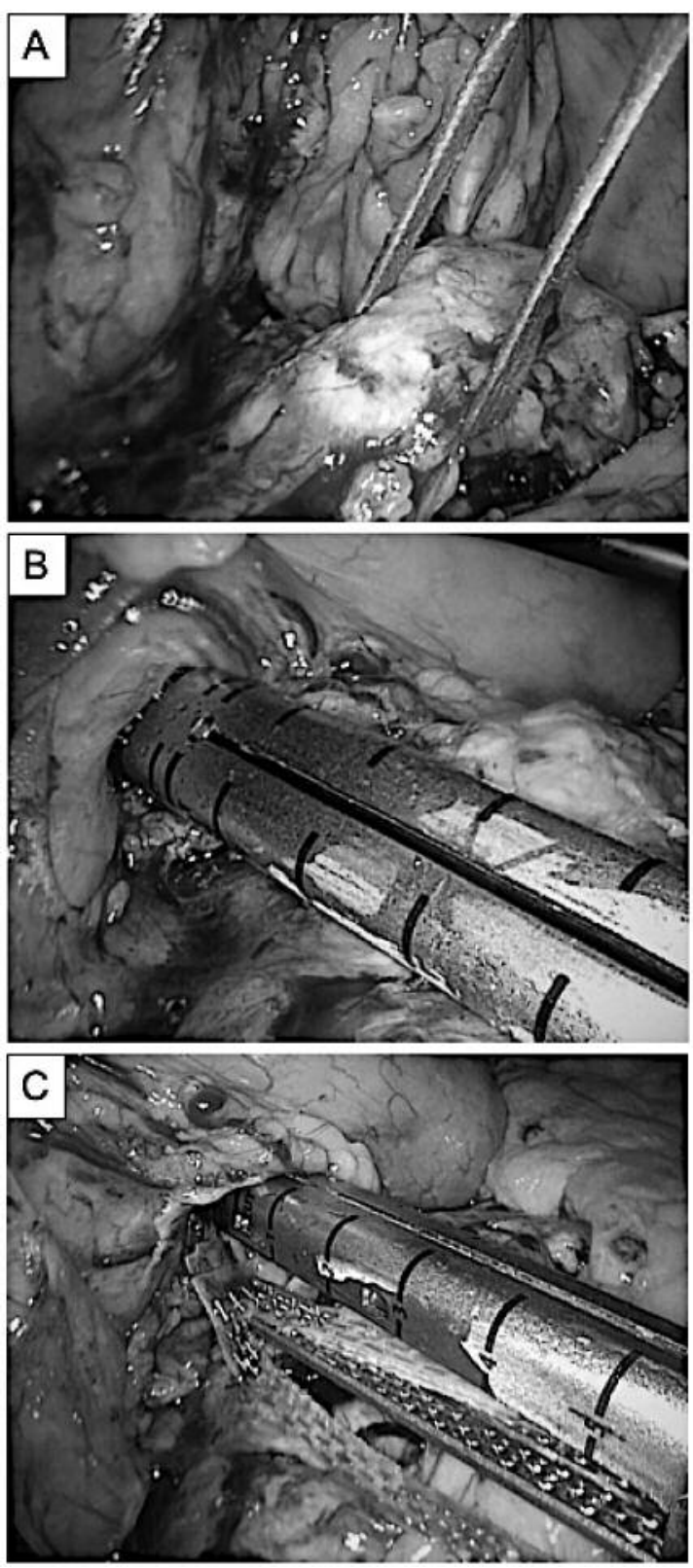

Figure 2. The operative schemas of the case with laparoscopic distal pancreatectomy $(D P)$ are demonstrated. (A) The parenchyma of the pancreas just above the portal/superior mesenteric vein was isolated and controlled with tape. (B) The pancreas was closed using staplers with polyglycolic acid (PGA) felt. (C) When the stapler with PGA felt is removed, the tip of the PGA felt is not divided. Gentle handling of stapler is especially needed during the removal of the stapler from the pancreas.

Kawai et al. reported that a pancreas thickness greater than $12 \mathrm{~mm}$ significantly increased POPF after DP using stapler closure (8). The thickness of the pancreatic parenchyma should be one of the important considerations during the applications of staples; however, the softness of pancreatic parenchyma is
Table I. The relationship between the PGA felt with staplers and POPF.

\begin{tabular}{lcc}
\hline & POPF & POPF (B or C) \\
\hline PGA felt $(-)(\mathrm{n}=20)$ & $9(45 \%)$ & $6(30 \%)$ \\
PGA felt $(+)(\mathrm{n}=22)$ & $4(18 \%)^{*}$ & $1(5 \%)^{* *}$ \\
\hline
\end{tabular}

PGA, Polyglycolic acid; POPF, postoperative pancreatic fistula. $* p=0.0583,{ }^{* *} p=0.0216$.

another consideration. For example, a very soft pancreas of more than 13-mm thickness would be safely compressed, while a hard pancreas of 11-mm thickness could not be compressed. For the safe compression of pancreatic parenchyma using staplers, both the thickness and softness of the pancreas should be taken into consideration simultaneously.

To avoid tearing of pancreatic parenchyma, the maintenance of pancreatic capsule during the division of the pancreas is another important concern. As a matter of course, the pancreatic capsule is thinner than those of other organs, such as the digestive tract or the liver. Some authors have emphasized that prolonged peri-firing compression of staplers could prevent POPF (9). However, our earlier trial showed the opposite (7). As we mentioned in this report, the time required for the procedure should not be the main concern; rather, the maintenance of the capsule and the care taken not to tear the parenchyma should be the paramount concerns.

Kurahara et al. (10) and Hamilton et al. (11) reported that mesh reinforcement of the pancreatic transection decreased POPF; however, details of the material of mesh or thickness of the staples were not discussed in these papers. Yet, these details are very important for the establishment of the ideal stapling system for DP. The reinforcement of the pancreatic transection line using anything else should be an important concept to maintain the pancreatic capsule and to avoid tearing of pancreatic parenchyma; however, the applicable thickness of the tissue would vary according to the thickness of reinforcement materials. Taking into consideration the original thickness of the pancreas, the development of a cartridge with PGA felt that has thicker staples is important for use in this challenging field. However, the deeper the staples go, the greater the risk of error in the stapling of the main pancreatic duct. Further in-depth research is needed for the establishment of the ideal staplers for DP.

\section{Conclusion}

The use of a linear stapling device with PGA felt preattached for the pancreatic stump closure during DP was found to be feasible and significantly suppressed Grade B or C POPF. 


\section{References}

1 Diener MK, Seiler CM, Rossion I, Kleeff J, Glanemann M, Butturini G, Tomazic A, Bruns CJ, Busch OR, Farkas S, Belyaev O, Neoptolemos JP, Halloran C, Keck T, Niedergethmann M, Gellert K, Witzigmann H, Kollmar O, Langer P, Steger U, Neudecker J, Berrevoet F, Ganzera S, Heiss MM, Luntz SP, Bruckner T, Kieser M and Büchler MW: Efficacy of stapler versus hand-sewn closure after distal pancreatectomy (DISPACT): A randomised, controlled multicentre trial. Lancet 377: 1514-1522, 2011.

2 Hassenpflug M, Hinz U, Strobel O, Volpert J, Knebel P, Diener MK, Doerr-Harim C, Werner J, Hackert T and Büchler MW: Teres ligament patch reduces relevant morbidity after distal pancreatectomy (the DISCOVER Randomized Controlled Trial). Ann Surg 264: 723-730, 2016.

3 Weniger M, D'Haese JG, Crispin A, Angele MK, Werner J and Hartwig W: Autologous but not fibrin sealant patches for stump coverage reduce clinically relevant pancreatic fistula in distal pancreatectomy: A systematic review and meta-analysis. World J Surg 40: 2771-2781, 2016.

4 Hüttner FJ, Mihaljevic AL, Hackert T, Ulrich A, Büchler MW and Diener MK: Effectiveness of Tachosil(@) in the prevention of postoperative pancreatic fistula after distal pancreatectomy: A systematic review and meta-analysis. Langenbecks Arch Surg 401: 151-159, 2016.

5 Kawai M, Hirono S, Okada K, Sho M, Nakajima Y, Eguchi H, Nagano H, Ikoma H, Morimura R, Takeda Y, Nakahira S, Suzumura K, Fujimoto J and Yamaue H: Randomized controlled trial of pancreaticojejunostomy versus stapler closure of the pancreatic stump during distal pancreatectomy to reduce pancreatic fistula. Ann Surg 264: 180-187, 2016.
6 Bassi C, Dervenis C, Butturini G, Fingerhut A, Yeo C, Izbicki J, Neoptolemos J, Sarr M, Traverso W and Buchler M; International Study Group on Pancreatic Fistula Definition. Postoperative pancreatic fistula: An international study group (ISGPF) definition. Surgery 138: 8-13, 2005.

7 Chikamoto A, Hashimoto D, Ikuta Y, Tsuji A, Abe S, Hayashi H, Imai K, Nitta H, Ishiko T, Watanabe M, Beppu T and Baba $\mathrm{H}$ : Effects of the closing speed of stapler jaws on bovine pancreases. Surg Endosc 28: 336-340, 2014.

8 Kawai M, Tani M, Okada K, Hirono S, Miyazawa M, Shimizu A, Kitahata Y and Yamaue H: Stump closure of a thick pancreas using stapler closure increases pancreatic fistula after distal pancreatectomy. Am J Surg 206: 352-359, 2013.

9 Nakamura M, Ueda J, Kohno H, Aly MY, Takahata S, Shimizu $\mathrm{S}$ and Tanaka M: Prolonged peri-firing compression with a linear stapler prevents pancreatic fistula in laparoscopic distal pancreatectomy. Surg Endosc 25: 867-871, 2011.

10 Kurahara H, Maemura K, Mataki Y, Sakoda M, Iino S, Hiwatashi K, Ishigami S, Ueno S, Shinchi $H$ and Natsugoe S: Closure of the pancreas in distal pancreatectomy: Comparison between bare stapler and reinforced stapler. Hepatogastroenterol 61(136): 2367-2370, 2014.

11 Hamilton NA, Porembka MR, Johnston FM, Gao F, Strasberg SM, Linehan DC and Hawkins WG: Mesh reinforcement of pancreatic transection decreases incidence of pancreatic occlusion failure for left pancreatectomy: A single-blinded, randomized controlled trial. Ann Surg 255: 1037-1042, 2012.

Received February 7, 2017

Revised March 6, 2017

Accepted March 7, 2017 